\title{
Decreased Expression of Estrogen Receptors Is Associated with Tumorigenesis in Papillary Thyroid Carcinoma
}

\author{
Chen-Kai Chou ${ }^{1}$, Shun-Yu Chi ${ }^{2}$, Yi-Yung Hung ${ }^{3}$, Yi-Chien Yang ${ }^{4}$, Hung-Chun Fu ${ }^{5} \oplus$, Jia-He Wang ${ }^{1}$, \\ Chueh-Chen Chen ${ }^{1}$ and Hong-Yo Kang ${ }^{5,6,7, * \mathbb{D}}$
}

1 Division of Endocrinology and Metabolism, Department of Internal Medicine, Kaohsiung Chang Gung Memorial Hospital, College of Medicine, Chang Gung University, Kaohsiung 83301, Taiwan; chou@cgmh.org.tw (C.-K.C.); kid1412310@gmail.com (J.-H.W.); masaki1225151@yahoo.com.tw (C.-C.C.)

2 Department of Surgery, Kaohsiung Chang Gung Memorial Hospital, College of Medicine, Chang Gung University, Kaohsiung 83301, Taiwan; abraban@cgmh.org.tw

3 Department of Psychiatry, Kaohsiung Chang Gung Memorial Hospital, College of Medicine, Chang Gung University, Kaohsiung 83301, Taiwan; ian670523@cgmh.org.tw

4 Department of Dermatology, Kaohsiung Chang Gung Memorial Hospital, College of Medicine, Chang Gung University, Kaohsiung 83301, Taiwan; yichienyang@gmail.com

5 Department of Obstetrics and Gynecology, Kaohsiung Chang Gung Memorial Hospital, College of Medicine, Chang Gung University, Kaohsiung 83301, Taiwan; allen133@cgmh.org.tw

6 Graduate Institute of Clinical Medical Sciences, Chang Gung University, Kaohsiung 83301, Taiwan

7 Center for Hormone and Reproductive Medicine Research, Department of Obstetrics and Gynecology, Kaohsiung Chang Gung Memorial Hospital, College of Medicine, Chang Gung University, Kaohsiung 83301, Taiwan

* Correspondence: hkang3@mail.cgu.edu.tw; Tel.: +886-7-731-7123 (ext. 8898)

\section{check for}

updates

Citation: Chou, C.-K.; Chi, S.-Y.; Hung, Y.-Y.; Yang, Y.-C.; Fu, H.-C.; Wang, J.-H.; Chen, C.-C.; Kang, H.-Y. Decreased Expression of Estrogen Receptors Is Associated with Tumorigenesis in Papillary Thyroid Carcinoma. Int. J. Mol. Sci. 2022, 23, 1015. https://doi.org/10.3390/ ijms23031015

Academic Editor:

Alfred King-Yin Lam

Received: 29 November 2021

Accepted: 14 January 2022

Published: 18 January 2022

Publisher's Note: MDPI stays neutral with regard to jurisdictional claims in published maps and institutional affiliations.

Copyright: (C) 2022 by the authors. Licensee MDPI, Basel, Switzerland. This article is an open access article distributed under the terms and conditions of the Creative Commons Attribution (CC BY) license (https:// creativecommons.org/licenses/by/ $4.0 /)$.

\begin{abstract}
Papillary thyroid carcinomas (PTC), which is derived from thyroid follicular cells, is the most commonly differentiated thyroid cancer with sex disparity. However, the role of estrogen receptors (ERs) in the pathogenesis of PTC remains unclear. The present study aimed to determine the association of ER mRNA expression levels with clinicopathologic features in PTC. To that aim, the mRNA levels of ESR1 (ER $\alpha 66), E S R 1$ (ER $\alpha 36), E S R 2$, and G-protein-coupled estrogen receptor 1 (GPER1) in snap-frozen tissue samples from PTCs and adjacent normal thyroid tissues were determined using quantitative reverse transcription polymerase chain reaction (RT-qPCR), and the correlation between ER mRNA expression levels and clinicopathologic features was analyzed. The expression of ER $\alpha 66, E R \alpha 36, E R \beta$, and GPER1 was lower in PTC specimens than in adjacent normal thyroid tissues. Moreover, low GPER1 expression was associated with extrathyroidal extension. There was no obvious difference in expression of ERs between PTC specimens from male and female patients. In conclusion, our findings highlight the importance of ERs in PTC tumorigenesis.
\end{abstract}

Keywords: papillary thyroid carcinoma; estrogen receptors; tumorigenesis; sex difference

\section{Introduction}

Papillary thyroid carcinoma (PTC), which is derived from thyroid follicular cells, is the most common form of well-differentiated thyroid cancer [1]. The prevalence of PTC has increased in recent decades, with female cases accounting for as many as $60-80 \%$ of the PTC cases in different populations and geographical areas [2]. Whilst women have an increased incidence of thyroid tumors, male sex is an unfavorable prognostic factor in PTC [3,4]. Therefore, sex hormones and the consequences derived from their associated signaling may play pivotal roles in the pathogenesis of PTC. Many advances in the diagnosis and management of PTC have been made; however, the influence of molecular factors on the development of PTC in different genders and the association of these factors with clinicopathological features remain to be elucidated. 
Sex hormone receptors are a group of steroid hormone receptors including androgens, estrogen, and progesterone [5]. Our previous study [6] investigated the impact of androgen receptor (AR) gene expression on the clinical features and progression of PTC. Our findings suggested that sex steroids and their receptors may play an important role in PTC tumorigenesis. Classical estrogen signaling is mediated through estrogen receptors (ERs), which are members of a large family of nuclear transcription factors [7]. The estrogen receptors $\alpha(E R \alpha)$ and $\beta(E R \beta)$ are two distinct ERs encoded by ESR1 (NR3A1) and ESR2 (NR3A2), respectively [8,9]. E2 and the estrogen receptors, $\mathrm{ER} \alpha$ and $\mathrm{ER} \beta$, have also been shown to participate in the pathology of thyroid cancer $[10,11]$. ER $\beta$ was demonstrated as having a protective role in carcinogenesis by regulating antiproliferative and proapoptotic signals, and loss of ER $\beta$ leads to unfavorable prognosis in thyroid cancers [12-15]. However, their expression patterns vary considerably, which hinders the identification of their role in the pathogenesis of thyroid cancer. Furthermore, recent studies have focused on ER $\alpha 36$, a novel $36 \mathrm{kDa}$ variant of the traditional full-length $\mathrm{ER} \alpha$, and the transmembrane estrogen receptor G-protein-coupled estrogen receptor 1 (GPER1). Nevertheless, although the importance of ERs in breast and prostate cancers is well established [16,17], little is known about the role of these ERs in tumorigenesis of PTC.

A better understanding of the clinical relevance of ERs in PTC initiation and progression may aid in the identification of novel therapeutic targets and molecular markers. However, there is limited and varying information on the relationship between ER expression and its correlation with clinical features in male and female PTC cases. Here, we simultaneously examined ESR1 (ER $\alpha 66)$, ESR1 (ER $\alpha 36), E S R 2$, and GPER1 mRNA expression levels in PTC specimens using quantitative reverse transcription polymerase chain reaction (RT-qPCR), and we assessed the correlation between ER expression and clinicopathologic characteristics in PTC.

\section{Results}

\subsection{Patient Characteristics}

This prospective study included 103 patients with PTC (82 women and 21 men) who received standard treatment, including surgery, radioactive iodine therapy, and thyroid hormone therapy, between August 2019 and July 2021 at the Kaohsiung Chang Gung Memorial Hospital, Kaohsiung, Taiwan. The clinicopathological features of these cases are shown in Table 1.

Table 1. Clinicopathological features of the papillary thyroid carcinoma (PTC) cases examined in this study $(n=103)$.

\begin{tabular}{cc}
\hline Clinical Features & $\boldsymbol{n} \mathbf{( \% )}$ \\
\hline Age at the time of diagnosis (years) & $47.18 \pm 12.82$ \\
Sex (male/female) & $21 / 82$ \\
Tumor size (cm) & $1.90 \pm 1.10$ \\
Lymph node metastasis & $38(36.8 \%)$ \\
Extrathyroidal extension & $30(29.1 \%)$ \\
Tumor staging (AJCC) ${ }^{a}$ & \\
Low-risk $_{\text {High-risk }}$ & $93(90.2 \%)$ \\
Distant metastasis & $10(9.7 \%)$ \\
\hline
\end{tabular}

a The low-risk group consisted of patients aged $\leq 55$ years with stage I PTC and those aged $>55$ years with stage I or II PTC according to the American Joint Committee on Cancer (AJCC). The remaining patients were defined as the high-risk group.

\subsection{ER Expression Is Lower in PTC Specimes Than in Adjacent Normal Thyroid Tissues}

The expression of ESR1 (ER $\alpha 66)$, ESR1 (ER $\alpha 36), E S R 2$, and GPER1 was analyzed in these samples by RT-qPCR. As shown in Figure 1, the levels of all mRNAs were significantly lower in PTC specimens than in the surrounding normal parenchyma (Figure 1A-D). A cycle threshold $(\mathrm{Ct})$ value $>40$ was defined as "not detectable" in this study; undetectable 
Ct values were only observed in PTC tumor specimens. Notably, only $16.5 \%, 19.4 \%, 30.1 \%$, and $33 \%$ of the PTC samples showed upregulated expression of ER $\alpha 66, E R \alpha 36, E R \beta$, and GPER1, respectively. In contrast, the expression of ER $\alpha 66, E R \alpha 36, E R \beta$, and GPER1 was classified as downregulated or undetectable in $83.5 \%, 80.6 \%, 69.9 \%$, and $67 \%$ of all samples (Figure 2A-D).

A

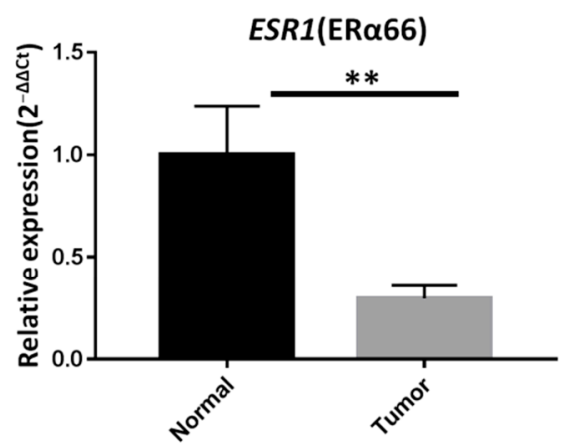

C

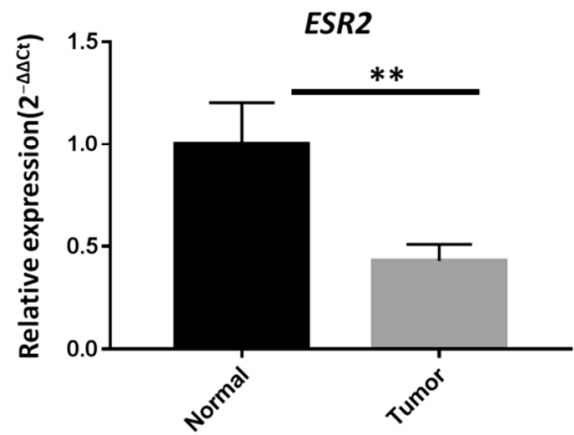

B

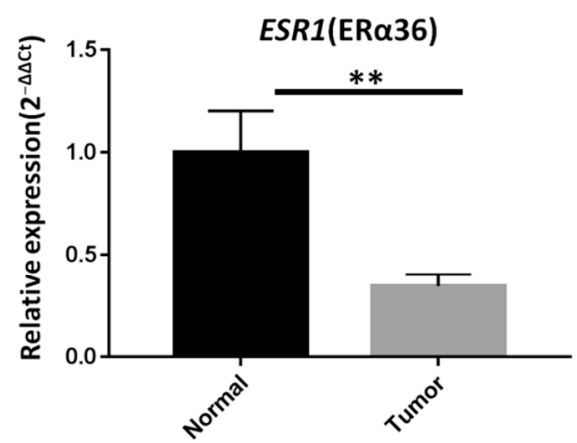

D

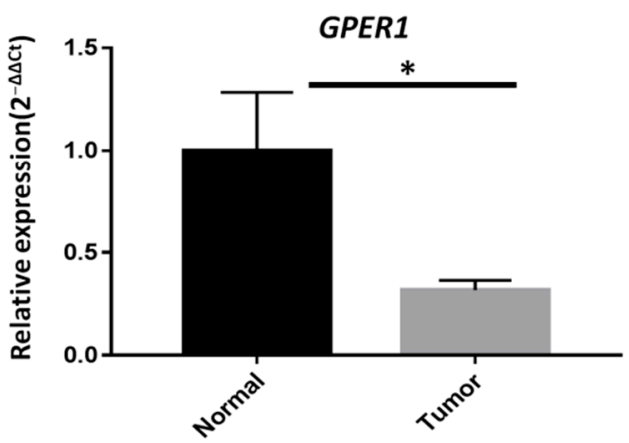

Figure 1. ER mRNA expression is lower in papillary thyroid carcinoma (PTC) specimens than in adjacent normal thyroid tissues. Quantitative reverse transcription polymerase chain reaction (RT-qPCR) analysis of (A) full-length estrogen receptor 1 (ER $\alpha 66),($ B) $36 \mathrm{kDa}$ version of ESR1 (ER $\alpha 36)$, (C) ER $\beta$, and (D) G-protein-coupled estrogen receptor 1 (GPER1) mRNA expression levels in PTC specimens $(n=103)$ and paired adjacent normal thyroid tissues. The fold change values indicate the relative change in the expression levels between samples and the internal control (18S rRNA), assuming that the expression level of $18 \mathrm{~S}$ rRNA in each sample was set to 1 . Relative mRNA expression levels in PTC specimens were normalized to adjacent normal tissues ( $\mathrm{T} / \mathrm{N}$ fold change). The mRNA expression levels of ER $\alpha 66, \mathrm{ER} \alpha 36, \mathrm{ER} \beta$, and GPER1 were significantly lower in tumor tissues than in matched adjacent normal tissues. Fold change in mRNA expression levels in tumor samples was calculated relative to that in paired normal thyroid tissue; ${ }^{* *} p<0.005,{ }^{*} p<0.05$.

We further analyzed ER expression according to different gender categories. The mRNA expression levels of ER $\alpha 66$ and ER $\alpha 36$ were significantly $(p<0.05)$ lower in PTC tumor specimens than in adjacent normal tissues in both female and male patients (Figure 3 ). Moreover, the mRNA expression levels of ESR2 and GPER1 were also significantly lower in PTC tumor specimens than in adjacent normal tissues in female patients. However, there was no obvious difference in ER expression between PTC specimens when comparing female and male patients (Figure 3).

We then analyzed the GDC TCGA Thyroid Cancer (THCA) dataset describing ER expression in PTC specimens, which is publicly available through the University of California Santa Cruz (UCSC) Xena Browser [18]. These data further confirmed that the expression levels of ER $\alpha, E R \beta$, and GPER1 are lower in PTC specimens than in normal human thyroid tissues (Figure S1). We also evaluated data from microarray-based RNA profiling analysis using the Gene Expression Omnibus (GEO) datasets GSE6004, GSE165724, and GSE153659; the findings further confirmed that ER expression is lower in PTC specimens than in normal 
human thyroid tissues (Figure S1). In agreement with our results (Figure 3), we observed significantly lower mRNA expression levels of ESR2 and GPER1 in PTC specimens from both male and female patients in the GSE165724 and GSE153659 datasets (Figure S2). However, data on the expression of specific ER $\alpha$ variants (ER $\alpha 66$ and ER $\alpha 36)$ are not available from these datasets without accession numbers.

A

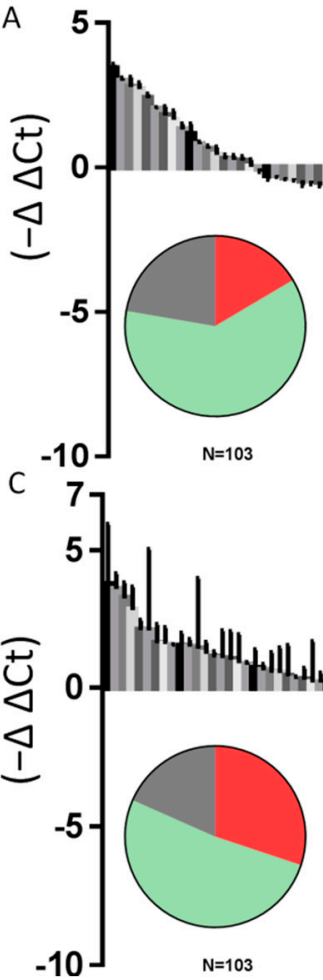

ESR1(ER $\alpha 66)$

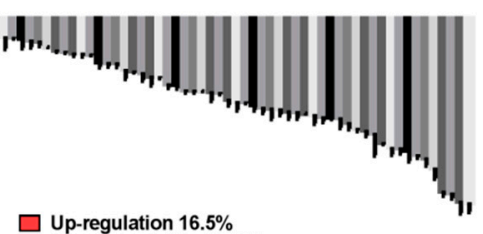

Up-regulation $16.5 \%$

Nown-detectable $22.3 \%$

ESR2

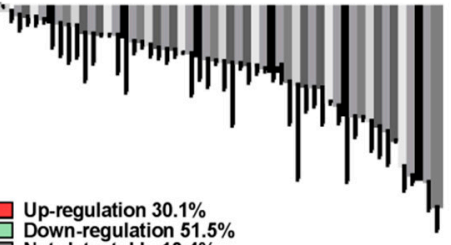

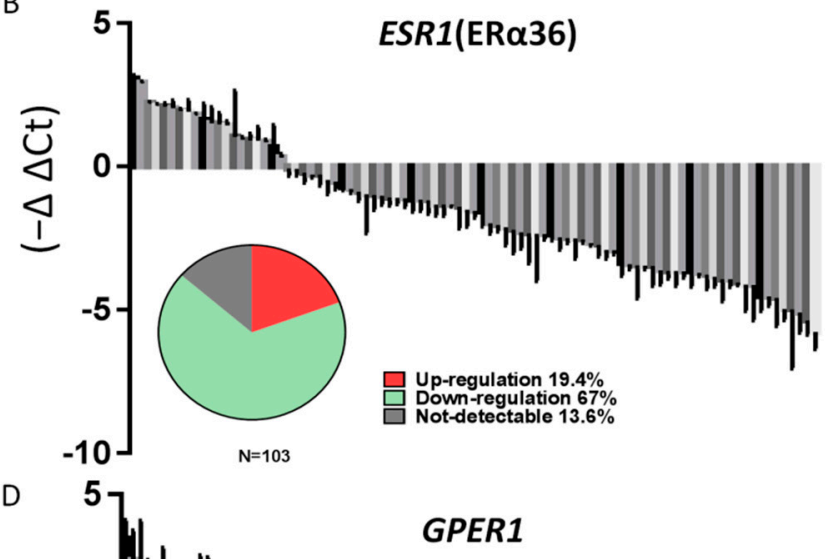

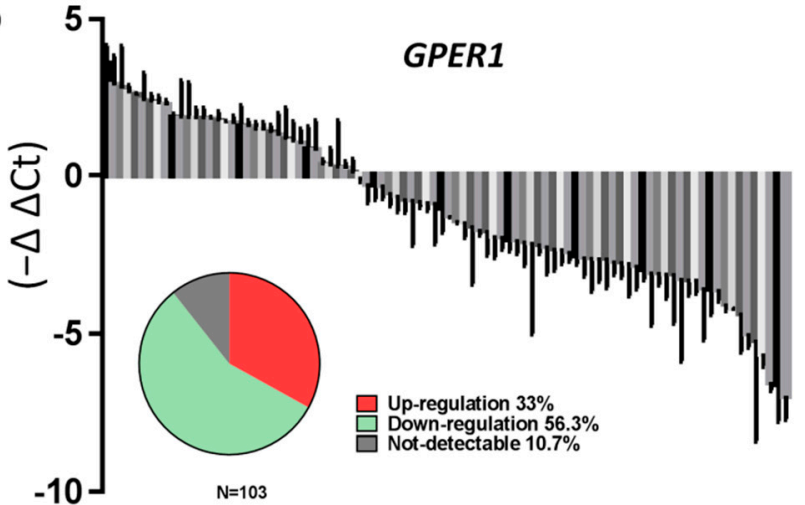

Figure 2. The majority of patients with PTC show lower ERs expression in cancer specimens than in adjacent normal thyroid tissues. Relative mRNA expression levels of (A) ER $\alpha 66$, (B) ER $\alpha 36,(\mathbf{C}) \mathrm{ER} \beta$, and (D) GPER1 in PTC $(n=103)$ samples normalized to that in adjacent normal tissues ( $\mathrm{T} / \mathrm{N}$ fold change). The pie charts show the proportion of samples with upregulated, downregulated, and undetectable expression.

\subsection{Correlation of ER Expression with Clinicopathological Characteristics in PTC}

The correlations between ESR1 (ER $\alpha 66)$, ESR1 (ER $\alpha 36)$, ESR2, and GPER1 mRNA expression levels and the demographic and clinical characteristics of the patients were further assessed. GPER1 mRNA expression level was significantly lower in patients with extrathyroidal extension than in those without $(p<0.05$; Table 2$)$. However, the patterns of ER mRNA expression level did not differ significantly among different sex and age groups, tumor stages, or patients with and without lymph node metastasis (Table 2).

To investigate whether ER expression is involved in thyroid cancer cell tumorology, the mRNA expression levels of ER $\alpha 66, \mathrm{ER} \alpha 36, \mathrm{ER} \beta$, and GPER1 were assessed in various thyroid cancer cell lines and a normal thyroid cell line. As demonstrated in Figure 4, their expression was significantly lower in PTC cancer cell lines (TPC-1 and MDAT) and anaplastic thyroid cancer (ATC) cell line (8505C) than in the normal thyroid cell line (Nthyori-3-1). This result suggests that decreased ER expression may play an important role in thyroid tumorigenesis and dedifferentiation. 

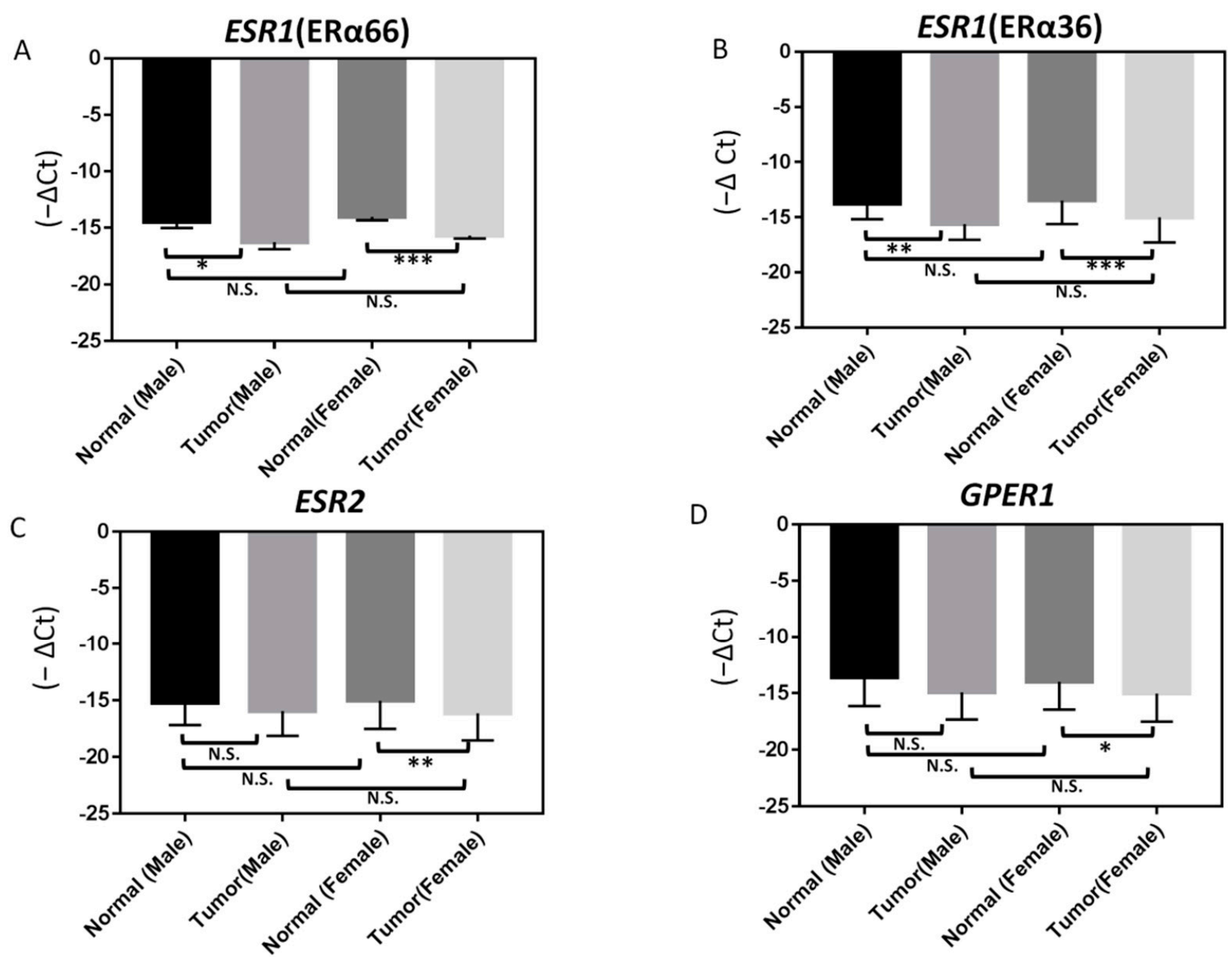

Figure 3. Differences in ERs expression between normal and papillary thyroid carcinoma (PTC; tumor) samples from male and female patients as determined by RT-qPCR: (A) ER $\alpha 66$, (B) ER $\alpha 36$, (C) ER $\beta$, and (D) GPER1. In samples from female patients, the expression of ER $\beta$ and GPER1 is significantly lower in PTC specimens than in adjacent normal tissues. In contrast, the expression of ER $\alpha 66$ and ER $\alpha 36$ in PTC specimens is significantly lower than in adjacent normal tissues in both male and female patients; ${ }^{* * *} p<0.001,{ }^{* *} p<0.005,{ }^{*} p<0.05$. N.S.: not significant.

Table 2. Association of estrogen receptor (ER) mRNA expression levels with the clinicopathological features of papillary thyroid carcinoma (PTC) cases $(n=103)$.

\begin{tabular}{|c|c|c|c|c|c|c|c|c|c|}
\hline \multirow{2}{*}{\multicolumn{2}{|c|}{ Clinical Features }} & \multicolumn{2}{|c|}{$E R \alpha 66$} & \multicolumn{2}{|c|}{$\mathrm{ER} \alpha 36$} & \multicolumn{2}{|c|}{$E R \beta$} & \multicolumn{2}{|c|}{ GPER1 } \\
\hline & & $2^{-(\Delta \Delta C t)}$ & $p$ & $2^{-(\Delta \Delta C t)}$ & $p$ & $2^{-(\Delta \Delta C t)}$ & $p$ & $2^{-(\Delta \Delta C t)}$ & $p$ \\
\hline Age (years) & $\begin{array}{l}<55 \\
\geq 55\end{array}$ & $\begin{array}{l}1.77 \pm 0.28 \\
1.23 \pm 0.21\end{array}$ & 0.60 & $\begin{array}{l}1.94 \pm 0.22 \\
2.49 \pm 0.44\end{array}$ & 0.59 & $\begin{array}{l}1.11 \pm 0.29 \\
0.66 \pm 0.14\end{array}$ & 0.09 & $\begin{array}{c}1.89 \pm 0.31 \\
2.310 .83\end{array}$ & 0.63 \\
\hline Sex & $\begin{array}{l}\text { Feale } \\
\text { Male }\end{array}$ & $\begin{array}{l}1.67 \pm 0.23 \\
1.25 \pm 0.30\end{array}$ & 0.47 & $\begin{array}{c}1.44 \pm 0.23 \\
0.8 \pm 0.43\end{array}$ & 0.06 & $\begin{array}{l}1.10 \pm 0.24 \\
0.99 \pm 0.22\end{array}$ & 0.44 & $\begin{array}{l}1.68 \pm 0.25 \\
2.24 \pm 0.64\end{array}$ & 0.40 \\
\hline $\begin{array}{l}\text { Lymph node } \\
\text { metastasis }\end{array}$ & $\begin{array}{l}\text { Absent } \\
\text { Present }\end{array}$ & $\begin{array}{l}1.43 \pm 0.24 \\
1.84 \pm 0.33\end{array}$ & 0.36 & $\begin{array}{l}1.95 \pm 0.20 \\
1.76 \pm 0.42\end{array}$ & 0.49 & $\begin{array}{l}1.21 \pm 0.35 \\
0.95 \pm 0.15\end{array}$ & 0.74 & $\begin{array}{l}2.22 \pm 0.50 \\
1.79 \pm 0.39\end{array}$ & 0.70 \\
\hline $\begin{array}{c}\text { Extrathyroidal } \\
\text { extension }\end{array}$ & $\begin{array}{l}\text { Absent } \\
\text { Present }\end{array}$ & $\begin{array}{l}1.76 \pm 0.27 \\
1.03 \pm 0.16\end{array}$ & 0.79 & $\begin{array}{c}1.06 \pm 0.22 \\
1.8 \pm 0.45\end{array}$ & 0.16 & $\begin{array}{l}0.83 \pm 0.12 \\
1.65 \pm 0.62\end{array}$ & 0.12 & $\begin{array}{c}2.2 \pm 0.45 \\
0.97 \pm 0.22\end{array}$ & $0.04^{b}$ \\
\hline $\begin{array}{l}\text { Tumor staging } \\
(\text { AJCC })^{a}\end{array}$ & $\begin{array}{l}\text { Low } \\
\text { High }\end{array}$ & $\begin{array}{l}1.62 \pm 0.22 \\
0.95 \pm 0.23\end{array}$ & 0.60 & $\begin{array}{l}1.1 \pm 0.20 \\
2.7 \pm 0.91\end{array}$ & 0.11 & $\begin{array}{l}1.09 \pm 0.23 \\
1.05 \pm 0.36\end{array}$ & 0.76 & $\begin{array}{l}1.86 \pm 0.33 \\
0.90 \pm 0.73\end{array}$ & 0.19 \\
\hline
\end{tabular}

a The low-risk group consisted of patients aged $\leq 55$ years with stage I PTC and those aged $>55$ years with stage I or II PTC according to the American Joint Committee on Cancer (AJCC). The remaining patients were defined as the high-risk group. ${ }^{\mathrm{b}} p<0.05$. 
A

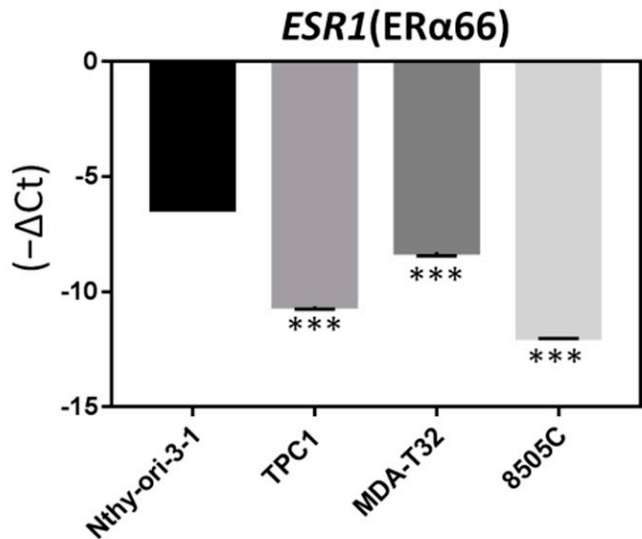

C

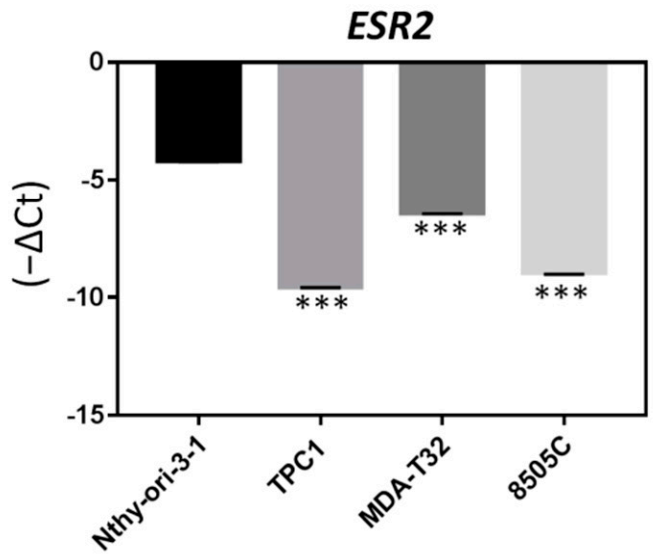

B

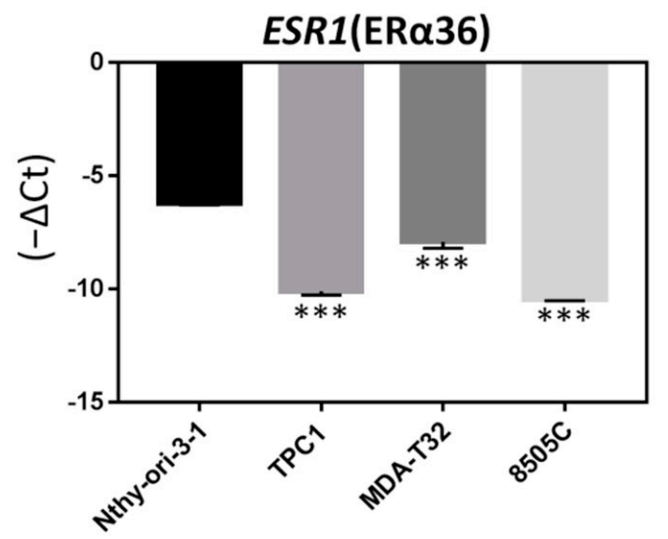

D

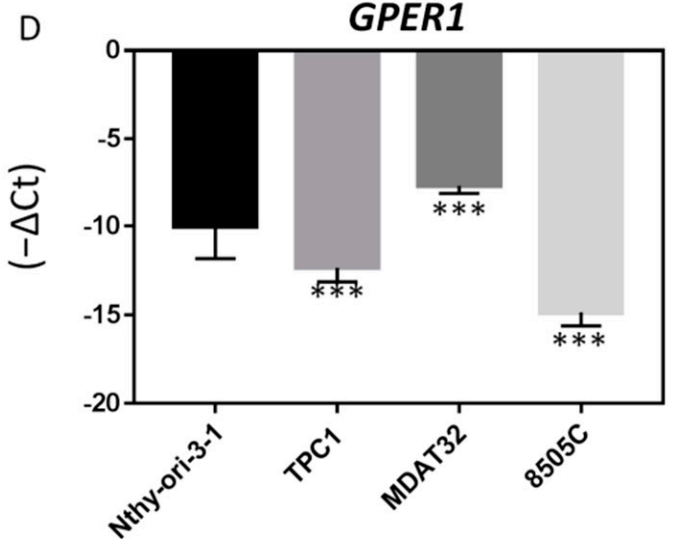

Figure 4. Endogenous ER mRNA expression levels are higher in PTC-derived cancer cells than in normal thyroid cells. The mRNA expression level of (A) ER $\alpha 66$, (B) ER $\alpha 36$, (C) ER $\beta$, and (D) GPER1 in the normal thyroid cell line, Nthy-ori-3-1, is higher than that in PTC-derived cancer cell lines (TPC1 and MDAT32) and the ATC-derived cancer cell line (8505C); ${ }^{* * *} p<0.001$ compared with normal thyroid cells.

\section{Discussion}

Estrogens are steroid hormones that play a key role not only in the regulation of reproductive organs, but also in tumor biology, including cell growth and differentiation in both males and females [9]. In the present study, we determined the mRNA expression levels of ERs in PTC specimens and examined the correlation with clinicopathological characteristics. In agreement with our previous study [6] which enrolled 71 PTC patients, we found that not only the mRNA expression levels of ER $\alpha 66$ and ER $\beta$ but also the expression levels of ER $\alpha 36$ and GPER1 were all decreased in PTC specimens compared to that in paired adjacent normal tissues. Furthermore, low GPER1 mRNA expression level was associated with extrathyroidal extension. These results suggest that, in addition to a decrease in ER $\beta$ expression [19], the decreased expression of other ERs is a common step in PTC tumor development.

Previous immunohistochemical studies have shown that ER $\alpha$ expression is greater in PTC tumors than in normal thyroid tissues, whereas ER $\beta$ expression is significantly lower in neoplastic than in nonneoplastic thyroid tissues $[20,21]$. Decreased ER $\beta$ mRNA and protein expression has been associated with the occurrence of nodular hyperplasia and PTC [22]. In contrast, there are contradictory reports regarding ER $\alpha$ and ER $\beta$ expression patterns, which have shown wide variations and discrepancies among studies as a result of different experimental methods, study designs, and sample sources [9]. The investigation of tumor biology, irrespective of the methodology employed, requires appropriate study controls. Using normal adjacent tissue as a control, as in this study, has many advantages over paired tumor tissue, such as the relative minimization of the variability and selection bias between 
study individuals. Previous studies have shown that DNA methylation may silence the promoter of ESR1 in several cancers [23,24]. For example, DNA hypermethylation is a major reason for the loss of ER $\alpha$ expression and confers a poor prognosis for breast cancer [25]. It is possible that epigenetic modifications of ESR1, such as DNA hypermethylation, may play an important role in PTC tumorigenesis. However, this hypothesis remains to be investigated in PTC.

A novel nonclassical ER pathway involves GPER1, formerly known as GPR30, which binds estrogen with high affinity and functions alongside the traditional nuclear ERs to regulate cellular and physiological responsiveness to estrogen [26]. In addition, ER $\alpha 36$ is believed to be involved in tumor behavior; it lacks both transcriptional activation domains and is located in the cytoplasm, where it mediates nongenomic estrogen signaling. Several studies have discussed the role of these novel ERs in the regulation of thyroid follicular cells in thyroid disease. A clinical study demonstrated that GPER1 expression is lower in goiter specimens than in normal thyroid tissues, suggesting that GPER1 may be involved in the pathogenesis of goiter [27]. ER $\alpha 36$ can crosstalk with the MAPK/ERK pathway and promote cell aggressiveness [28]. Here, we demonstrated that the mRNA expression level of GPER1 and ER $\alpha 36$ is decreased in PTC specimens compared to that in paired adjacent normal tissues. Our findings are in agreement with a recent study reporting the tumorigenesis role of decreased GPER1 expression according to in silico analyses of the GEO and TCGA databases [29]. Furthermore, in agreement with our findings showing that low GPER1 expression is associated with extrathyroidal extension, there is evidence that the activation of GPER1 inhibits epithelial-mesenchymal transition (EMT), which is accompanied by upregulation of E-cadherin and downregulation of N-cadherin and vimentin in goat mammary epithelial cells [30].

Recent studies have addressed the influence of ERs on thyroid cancer; however, the results have been inconsistent. Previous studies have demonstrated that higher ER $\alpha$ expression enhances cell proliferation. Furthermore, ER expression has been shown to be correlated with tumor size and the proliferation marker Ki-67 in PTC, reaffirming the role of $\mathrm{ER} \alpha$ in tumor growth [31]. However, a significantly higher proportion of tumors from disease-free patients have been shown to be ER $\alpha$ positive, indicating an inverse relationship between ER $\alpha$ expression and poor clinical outcomes [32]. In the current study, the pattern of ER mRNA expression levels did not differ significantly among different age groups, tumor stages, or patients with and without lymph node metastasis (Table 2). Similar to a previous study [33], we also found no significant differences in the expression levels of ERs in PTC samples from men and women with PTC. These data suggest that the expression level of ERs may not be directly involved in the disparities in PTC prevalence and progression between men and women. It is possible that the current cross-sectional study is limited by sample size and follow-up interval. The lack of longitudinal and prognostic factors hinders the determination of the role of ERs in PTC. These limitations could be overcome with larger sample sizes and adequate follow-up periods.

\section{Materials and Methods}

\subsection{Tumor Samples and Patient Information}

This is a prospective study composed of PTC patients treated between August 2019 and July 2021 at the Kaohsiung Chang Gung Memorial Hospital, Kaohsiung, Taiwan. We omitted those with follicular carcinoma, medullary cancer or anaplastic cancer. Patients aged less than 18 years or more than 80 years and those without an adequate follow-up period were also excluded. Tissue samples were snap-frozen in liquid nitrogen at the time of total thyroidectomy and subsequently stored in liquid nitrogen. Details concerning clinical data collection and tumor node metastasis classification for these samples were previously described elsewhere [34]. Patients that were aged $<55$ years with stage I PTC and those that were aged $<55$ years with stage I or II PTC were defined as the low-risk group according to the American Joint Commission on Cancer-International Union Against Cancer criteria [35]. The remaining patients were defined as the high-risk group. 


\subsection{RNA Extraction and Quantitative Reverse Transcription Polymerase Chain Reaction (RT-qPCR)}

Total RNA was extracted from surgical specimens $(\leq 50 \mathrm{mg})$ stored in DNA/RNA ShiledTM (ZYMO, Irvine, CA, USA) and thyroid cancer cell lines using Quick-RNATM Mini Prep kit (ZYMO, Irvine, CA, USA). cDNA templates were obtained by reversetranscribing $2 \mu \mathrm{g}$ of total RNA using the M-MLV Reverse Transcriptase Kit (Promega, Madison, WI, USA). The reaction conditions for the procedure were as follows: $70^{\circ} \mathrm{C}$ for 10 min with $2 \mu \mathrm{g}$ of RNA, $10 \mu \mathrm{M}$ of Oligo dT and dd $\mathrm{H}_{2} \mathrm{O} ; 42{ }^{\circ} \mathrm{C}$ for $1 \mathrm{~h} ; 95^{\circ} \mathrm{C}$ for $1 \mathrm{~min}$ with the previous mix and $5 \times$ MMLV RT buffer, $2.5 \mathrm{mM}$ dNTP, MMLV Reverse Transcriptase, and RNasin. The primers for real-time PCR were as follows: 18S rRNA, forward (5'-GTAACCCGTTGAACCCCATT-3') and reverse (5'-CCATCCAATCGGTAGTAGTG-3'); ER $\alpha 36$, forward (5'-CCAAGAATGTTCAACCACAACCT- $\left.3^{\prime}\right)$ and reverse (5'-GCACGGTT CATTAACATCTTTCTG-3'); ER $\alpha 66$, forward (5'-AAGAAAGAACAACATCAGCAGTAAA GTC $\left.-3^{\prime}\right)$ and reverse (5'-GGGCTATGGCTTGGTTAAACAT- $3^{\prime}$ ); ER $\beta$, forward (5'-TACTGA CCAACCTGGCAGACAG- $\left.3^{\prime}\right)$, forward (5'-AGCCGGTCCGGGTGCAAG-3') and reverse (5'-CCACCCAGAGCCCGAGGG-3'); GPER1, forward (5'-AGTCGGATGTGAGGTTCA-3'), and reverse $\left(5^{\prime}-\right.$ TCTGTGTGAGGAGTGCAA- $\left.3^{\prime}\right)$. The RT-qPCR was performed with $2 \mu \mathrm{L}$ of ten-fold-diluted cDNA using $7 \mu \mathrm{L}$ of Fast SYBR Green Master Mix (Applied Biosystems, Life Technologies, New York, NY, USA) and $0.5 \mu \mathrm{L}$ of $10 \mathrm{uM}$ forward and reverse primers. The reaction conditions for the procedure were as follows: $95^{\circ} \mathrm{C}$ for $20 \mathrm{~s}$, followed by 40 cycles of $95{ }^{\circ} \mathrm{C}$ for $3 \mathrm{~s}$ and $60^{\circ} \mathrm{C}$ for $30 \mathrm{~s}$. The protocol for RT-qPCR was according to the manufacturer's instructions.

\subsection{Thyroid Cancer Cell Culture}

Three human thyroid cancer cell lines (TPC1, MDA-T32, and 8505C) and one normal thyroid cell line (Nthy-ori-3-1) were used in this study. TPC1, MDA-T32 (American Type Culture Collection, cat\#30-2001, Manassas, VA, USA), and normal cell line Nthy-ori-3-1 (European Collection of Authenticated Cell Cultures (ECACC), Porton Down, Porton, UK) were routinely cultured in RPMI1640 containing 10\% fetal bovine serum (FBS), 100 units $/ \mathrm{mL}$ penicillin, and $2 \mathrm{mM}$ L-glutamine (Gibco, Carlsbad, CA, USA) at $37^{\circ} \mathrm{C}$ in a humidified chamber containing $5 \% \mathrm{CO}_{2}$. The $8505 \mathrm{C}$ cells (ECACC, Porton Down, Porton, UK) were routinely cultured in MEM containing 10\% fetal bovine serum (FBS), 100 units $/ \mathrm{mL}$ penicillin, and $1 \%$ sodium pyruvate.

\subsection{Bioinformatics Analysis}

The bioinformatics data on the ERs expression of PTC were publicly available from UCSC Xena Browser under GDC THCA datasets. The chosen phenotypic parameters were the sample type, gender, and histological type, which allowed easily selecting the PTC classical normal and tumor regions, male and female datasets, and genes of interest (ESR1, ESR2, and GPER1), before downloading the files for analysis. We also analyzed gene expression data from three microarray datasets (GSE6004, GSE165724, and GSE153659) from GEO datasets. The raw data file of this array was downloaded, and the values of the ERs were analyzed.

\subsection{Statistical Analyses}

Continuous variables, including ER expression in paired cancer and normal tissue from patients with PTC, were compared using Wilcoxon test. Correlations between ER expression levels and tumor characteristics were assessed by Mann-Whiney U-test analysis. All statistical analyses were performed using SPSS software (version 19.0; SPSS, Chicago, IL, USA). All $p$-values were two sided, with $p$-values $<0.05$ considered statistically significant. 


\section{Conclusions}

Our findings demonstrate that PTC specimens have reduced ER expression and that GPER1 expression is associated with extrathyroidal extension. These findings highlight the importance of ERs in the tumorigenesis and clinical presentation of PTC. Future studies with large sample sizes and appropriate follow-up periods will help to elucidate the association of ERs expression with overall survival and PTC-related death. This may facilitate personalized patient care by using the expression profiling of ERs as a prognostic factor to guide follow-up and management decisions.

Supplementary Materials: The following are available online at https:/ /www.mdpi.com/article/ 10.3390/ijms23031015/s1.

Author Contributions: Conceptualization, C.-K.C.; data curation, J.-H.W., C.-C.C. and H.-Y.K.; investigation, S.-Y.C., Y.-Y.H., Y.-C.Y. and J.-H.W.; methodology, J.-H.W. and H.-C.F.; project administration, J.-H.W., C.-K.C. and H.-Y.K.; resources, C.-K.C. and H.-Y.K.; supervision, H.-Y.K.; writing-original draft, C.-K.C.; writing-review and editing, S.-Y.C. and H.-Y.K. All authors have read and agreed to the published version of the manuscript.

Funding: The authors would like to thank the Chang Gung Memorial Hospital-Kaohsiung Medical Center, Kaohsiung, Taiwan (Contract No. CMRPG8K0702, CMRPG8L0321 and CMRPG8K0961) and the Ministry of Science and Technology of the Republic of China, Taiwan (Contract No. MOST 109-2314-B-182A-126-). The authors also thank the Chang Gung Medical Foundation Chang Gung Memorial Hospital Tissue Bank Core Lab (CMRPG8F1701) for excellent technical support and the Chang Gung Medical Foundation Chang Gung Memorial Hospital Anatomic Pathology for financially supporting this research.

Institutional Review Board Statement: The study was conducted according to the guidelines of the Declaration of Helsinki and approved by the Institutional Review Board of Chang Gung Memorial Hospital (ethics codes: 201901442B0, 201901442B0C501, 201902105B0, 202001740B0, and 202001740B0C501).

Informed Consent Statement: Informed consent was obtained from all subjects involved in the study.

Data Availability Statement: The raw data supporting the conclusions of this article will be made available by the authors, without undue reservation.

Acknowledgments: The authors thank Jacques Dumont from the Universite Libre de Bruxelles for providing the TPC-1 thyroid cancer cell line. The authors thank Shu-Fu Lin from the Department of Internal Medicine, Chang Gung Memorial Hospital, Taoyuan, Taiwan for providing the 8505C and Nthy-ori-3-1 cell lines.

Conflicts of Interest: The authors declare no conflict of interest.

\section{References}

1. Rahbari, R.; Zhang, L.; Kebebew, E. Thyroid cancer gender disparity. Future Oncol. 2010, 6, 1771-1779. [CrossRef] [PubMed]

2. Dean, D.S.; Gharib, H. Epidemiology of thyroid nodules. Best Pract. Res. Clin. Endocrinol. Metab. 2008, 22, 901-911. [CrossRef]

3. Hay, I.D.; Bergstralh, E.J.; Goellner, J.R.; Ebersold, J.R.; Grant, C.S. Predicting outcome in papillary thyroid carcinoma: Development of a reliable prognostic scoring system in a cohort of 1779 patients surgically treated at one institution during 1940 through 1989. Surgery 1993, 114, 1050-1057; discussion 1057-1058.

4. Guo, K.; Wang, Z. Risk factors influencing the recurrence of papillary thyroid carcinoma: A systematic review and meta-analysis. Int. J. Clin. Exp. Pathol. 2014, 7, 5393-5403. [PubMed]

5. Stanisic, V.; Lonard, D.M.; O'Malley, B.W. Modulation of steroid hormone receptor activity. Prog. Brain Res. 2010, 181, 153-176. [PubMed]

6. Chou, C.K.; Chi, S.Y.; Chou, F.F.; Huang, S.C.; Wang, J.H.; Chen, C.C.; Kang, H.Y. Aberrant Expression of Androgen Receptor Associated with High Cancer Risk and Extrathyroidal Extension in Papillary Thyroid Carcinoma. Cancers 2020, $12,1109$. [CrossRef] [PubMed]

7. Mangelsdorf, D.J.; Thummel, C.; Beato, M.; Herrlich, P.; Schutz, G.; Umesono, K.; Blumberg, B.; Kastner, P.; Mark, M.; Chambon, P.; et al. The nuclear receptor superfamily: The second decade. Cell 1995, 83, 835-839. [CrossRef]

8. Chen, G.G.; Zeng, Q.; Tse, G.M. Estrogen and its receptors in cancer. Med. Res. Rev. 2008, 28, 954-974. [CrossRef]

9. Derwahl, M.; Nicula, D. Estrogen and its role in thyroid cancer. Endocr. Relat. Cancer 2014, 21, T273-T283. [CrossRef] [PubMed]

10. Manole, D.; Schildknecht, B.; Gosnell, B.; Adams, E.; Derwahl, M. Estrogen promotes growth of human thyroid tumor cells by different molecular mechanisms. J. Clin. Endocrinol. Metab. 2001, 86, 1072-1077. [CrossRef] 
11. Lee, M.L.; Chen, G.G.; Vlantis, A.C.; Tse, G.M.; Leung, B.C.; van Hasselt, C.A. Induction of thyroid papillary carcinoma cell proliferation by estrogen is associated with an altered expression of Bcl-xL. Cancer J. 2005, 11, 113-121. [CrossRef] [PubMed]

12. Halon, A.; Nowak-Markwitz, E.; Maciejczyk, A.; Pudelko, M.; Gansukh, T.; Gyorffy, B.; Donizy, P.; Murawa, D.; Matkowski, R.; Spaczynski, M.; et al. Loss of estrogen receptor beta expression correlates with shorter overall survival and lack of clinical response to chemotherapy in ovarian cancer patients. Anticancer Res. 2011, 31, 711-718. [PubMed]

13. Mauro, L.V.; Dalurzo, M.; Carlini, M.J.; Smith, D.; Nunez, M.; Simian, M.; Lastiri, J.; Vasallo, B.; Bal de Kier Joffe, E.; Pallotta, M.G.; et al. Estrogen receptor beta and epidermal growth factor receptor as early-stage prognostic biomarkers of non-small cell lung cancer. Oncol. Rep. 2010, 24, 1331-1338. [PubMed]

14. Tallini, G.; Garcia-Rostan, G.; Herrero, A.; Zelterman, D.; Viale, G.; Bosari, S.; Carcangiu, M.L. Downregulation of p27KIP1 and Ki67/Mib1 labeling index support the classification of thyroid carcinoma into prognostically relevant categories. Am. J. Surg. Pathol. 1999, 23, 678-685. [CrossRef]

15. Heikkila, A.; Hagstrom, J.; Maenpaa, H.; Louhimo, J.; Siironen, P.; Heiskanen, I.; Haglund, C.; Arola, J. Loss of estrogen receptor Beta expression in follicular thyroid carcinoma predicts poor outcome. Thyroid 2013, 23, 456-465. [CrossRef] [PubMed]

16. Folkerd, E.; Dowsett, M. Sex hormones and breast cancer risk and prognosis. Breast 2013, 22, S38-S43. [CrossRef]

17. Daniels, N.A.; Nielson, C.M.; Hoffman, A.R.; Bauer, D.C.; Osteoporotic Fractures In Men Study, G. Sex hormones and the risk of incident prostate cancer. Urology 2010, 76, 1034-1040. [CrossRef]

18. Casper, J.; Zweig, A.S.; Villarreal, C.; Tyner, C.; Speir, M.L.; Rosenbloom, K.R.; Raney, B.J.; Lee, C.M.; Lee, B.T.; Karolchik, D.; et al. The UCSC Genome Browser database: 2018 update. Nucleic Acids Res. 2018, 46, D762-D769. [CrossRef]

19. Bardin, A.; Boulle, N.; Lazennec, G.; Vignon, F.; Pujol, P. Loss of ERbeta expression as a common step in estrogen-dependent tumor progression. Endocr. Relat. Cancer 2004, 11, 537-551. [CrossRef]

20. Magri, F.; Capelli, V.; Gaiti, M.; Villani, L.; Zerbini, F.; La Manna, L.; Rotondi, M.; Chiovato, L. ER-alpha and ER-beta expression in differentiated thyroid cancer: Relation with tumor phenotype across the TNM staging and peri-tumor inflammation. Endocrine 2015, 49, 429-435. [CrossRef]

21. Chen, G.G.; Vlantis, A.C.; Zeng, Q.; van Hasselt, C.A. Regulation of cell growth by estrogen signaling and potential targets in thyroid cancer. Curr. Cancer Drug Targets 2008, 8, 367-377. [CrossRef] [PubMed]

22. Dai, Y.J.; Qiu, Y.B.; Jiang, R.; Xu, M.; Zhao, L.; Chen, G.G.; Liu, Z.M. Concomitant high expression of ERalpha36, EGFR and HER2 is associated with aggressive behaviors of papillary thyroid carcinomas. Sci. Rep. 2017, 7, 12279. [CrossRef] [PubMed]

23. Yao, J.; Zhang, X.B.; Zhang, X.L.; Fu, W.L. Methylation status of oestrogen receptor alpha-A: A predictor of prognosis in leukaemias. Biosci. Rep. 2010, 30, 217-222. [CrossRef]

24. Wei, J.; Han, B.; Mao, X.Y.; Wei, M.J.; Yao, F.; Jin, F. Promoter methylation status and expression of estrogen receptor alpha in familial breast cancer patients. Tumour Biol. 2012, 33, 413-420. [CrossRef]

25. Ramos, E.A.; Camargo, A.A.; Braun, K.; Slowik, R.; Cavalli, I.J.; Ribeiro, E.M.; Pedrosa Fde, O.; de Souza, E.M.; Costa, F.F.; Klassen, G. Simultaneous CXCL12 and ESR1 CpG island hypermethylation correlates with poor prognosis in sporadic breast cancer. BMC Cancer 2010, 10, 23. [CrossRef]

26. Prossnitz, E.R.; Barton, M. Signaling, physiological functions and clinical relevance of the G protein-coupled estrogen receptor GPER. Prostaglandins Other Lipid Mediat. 2009, 89, 89-97. [CrossRef]

27. Weber, R.; Bertoni, A.P.; Bessestil, L.W.; Brum, I.S.; Furlanetto, T.W. Decreased Expression of GPER1 Gene and Protein in Goiter. Int. J. Endocrinol. 2015, 2015, 869431. [CrossRef]

28. Wang, Z.; Zhang, X.; Shen, P.; Loggie, B.W.; Chang, Y.; Deuel, T.F. A variant of estrogen receptor-\{alpha\}, hER-\{alpha\}36: Transduction of estrogen- and antiestrogen-dependent membrane-initiated mitogenic signaling. Proc. Natl. Acad. Sci. USA 2006, 103, 9063-9068. [CrossRef] [PubMed]

29. Bertoni, A.P.S.; Manfroi, P.A.; Tomedi, J.; Assis-Brasil, B.M.; de Souza Meyer, E.L.; Furlanetto, T.W. The gene expression of GPER1 is low in fresh samples of papillary thyroid carcinoma (PTC), and in silico analysis. Mol. Cell. Endocrinol. 2021, 535, 111397. [CrossRef]

30. Zhao, Y.; Yang, Z.; Miao, Y.; Fan, M.; Zhao, X.; Wei, Q.; Ma, B. G protein-coupled estrogen receptor 1 inhibits the epithelialmesenchymal transition of goat mammary epithelial cells via NF-kappaB signalling pathway. Reprod. Domest. Anim. 2021, 56, 1137-1144. [CrossRef] [PubMed]

31. Huang, Y.; Dong, W.; Li, J.; Zhang, H.; Shan, Z.; Teng, W. Differential expression patterns and clinical significance of estrogen receptor-alpha and beta in papillary thyroid carcinoma. BMC Cancer 2014, 14, 383. [CrossRef] [PubMed]

32. Sturniolo, G.; Zafon, C.; Moleti, M.; Castellvi, J.; Vermiglio, F.; Mesa, J. Immunohistochemical Expression of Estrogen Receptor-alpha and Progesterone Receptor in Patients with Papillary Thyroid Cancer. Eur. Thyroid J. 2016, 5, 224-230. [CrossRef] [PubMed]

33. Chen, D.; Qi, W.; Zhang, P.; Guan, H.; Wang, L. Expression of the estrogen receptor alpha, progesterone receptor and epidermal growth factor receptor in papillary thyroid carcinoma tissues. Oncol. Lett. 2015, 10, 317-320. [CrossRef] [PubMed]

34. Chou, C.K.; Chen, R.F.; Chou, F.F.; Chang, H.W.; Chen, Y.J.; Lee, Y.F.; Yang, K.D.; Cheng, J.T.; Huang, C.C.; Liu, R.T. miR-146b is highly expressed in adult papillary thyroid carcinomas with high risk features including extrathyroidal invasion and the BRAF(V600E) mutation. Thyroid 2010, 20, 489-494. [CrossRef] [PubMed]

35. Haugen, B.R.; Alexander, E.K.; Bible, K.C.; Doherty, G.M.; Mandel, S.J.; Nikiforov, Y.E.; Pacini, F.; Randolph, G.W.; Sawka, A.M.; Schlumberger, M.; et al. 2015 American Thyroid Association Management Guidelines for Adult Patients with Thyroid Nodules and Differentiated Thyroid Cancer: The American Thyroid Association Guidelines Task Force on Thyroid Nodules and Differentiated Thyroid Cancer. Thyroid 2016, 26, 1-133. [CrossRef] 